\title{
OS PRINCÍPIOS DA ADMINISTRAÇÃO PÚBLICA: ASPECTOS A CONSIDERAR
}

José de Almeida Leão *

Luiz de França Costa Filho **

SUMARIO: 1. Introdução; 2. Premissas metodológicas; 2.1 Sistema e tópica; 2.2 Eleiçăo do método; 3. Importância dos principios do direito; 4. Desenvolvimento do projeto. 5. Conclusāo; 6. Bibliografia.

SUMMARY: 1. Introduction; 2. Methodological premises; 2.1 System and topical; 2.2 Election of the method; 3. Importance of the principles of the right; 4. Development of the project. 5 . Conclusion; 6. Bibliography.

ÜBERSICHT: 1. Einführung; 2. Methodische Voraussetzungen; 2.1. System und Topik; 2.2. Methodenwahl; 3. Bedeutung der Rechtsprinzipien; 4. Entwicklung des Projekts; 5. Schlussfolgerung; 6. Bibliographie.

RESUMO: Trata-se de experiência desenvolvida em projeto de ensino. Buscou-se o emprego de técnica que carregasse no seu bojo a possibilidade de maior integração do conhecimento teórico acadèmico à realidade da vida, que pudesse contribuir para uma formação mais voltada aos ditames da contemporaneidade. Foram destacados os aspectos sistêmicos do direito e a possibilidade da utilização do pensamento tópico, dando-se ênfase às visões holística e reducionista.

* Professor e Coordenador do Colegiado do Curso de Diretio e Mestre em Direito Negocial pela Universidade Estadual de londrina.

* Doutor e mestre pela Johamnes Gutenberg Univeristä - Mainz e professor dos Cursos de Graduaçăo em Direito e do Mestrado em Dircito Negocial da Universidade Estadual de Londrina. 
Descreveu-se a razão da adoção de pluralidade metodológica, mas com o destaque para a técnica da problematizaçâo. Destacou-se a importância dos principios do direito e sua pertinencia à técnica tópica empregada no desenvolvimento do projeto de ensino.

ABSTRACT: The article treats about the experience developed in teaching project. The technique employment was looked for that carried in its salience the possibility of larger integration of the academic theoretical knowledge to the reality of the life, that could contribute to a formation more returned to the nowaday's ditames. It was outstanding the system aspects of the right and the possibility of the use of the topical thought, giving emphasis to the hole and reduce visions. The reason of the adoption of methodological plurality was described, but it was made with the prominence for the lechnique of the problematization. It stood out the importance of the principles of the right and its pertinence to the technique topical used in the development of the teaching project.

ZUSAMMENFASSUNG: Es handelt sich um entwickelte Erfahrung im Ausbildungsprojekt. Man bediente sich dabei der Technik, die die grössere Integrierung der akademischen theoretischen Kenntnis in die Realität des Lebens ermöglicht und die zu einer Ausbildung beitragen moge, die weitmöglichst auf die zeitgenössischen Regeln gerichtet ist. Hervorgehoben wurden die Systemaspekte des Rechts und de Moglichkeit der Benutzung des sachlichen Denkens, wobei die holistischen und reduktionistischen Standpunkte betont wurden. Es wurde der Grund der Annahme methodologisher Pluralitä beschrieben, aber unter Hervorhebung der Problematisierungstechnik. Es wurde auch die Wichtigheit der Rechtsprinzipien und ihrer Zugehorigkeit zur topischen Technik, die bei der Entwicklung des Ausbildungsprojekts angewandt wurde, betont.

PAlAVRAS-CHAVE: Método. Principios do direito Sistema. Tópica.

KEY-WORDS: Method. Beginnings of the law. System. Topical.

SCHLUSSELWÖRTER: Methode. Rechtsprinzipien. System. Topik. 


\section{Introdução}

$O$

presente apanhado trata de experiencia concretizada no desenrolar de projeto de ensino. O projeto teve como inspiração, o momento crítico por que passa o ensino juridico no Brasil, como de resto parece passar o ensino em todas as áreas do conhecimento.

Quando da mera especulação teórica desponta insuficiência e inadequaçăo para respostas aos anseios decorrentes das mansformaçóes sociais, parece mostrar-se o momento de se buscar a integrar hamoniosamente as construçós intelectuais abstratas ao campo da prática. Trata-se de refletir sobre a oportunidade de recuperar o valor e o prestigio da retórica. Tomando-se em mira que a administração da justiça, tem dado margem a uma atuação mais consentânea na interpretação e aplicação do direito, parece mostrar-se de grande praticidade a retomada da argumentaça como técnica de revigoramento e atualizaçăo do pensar juridico.

Objetivol-se, daí, no projeto, o desenvolvimento aplicativo de técnica que carregasse no seu bojo a possibilidade de maior integraça do conhecimento teónico académico à realidade da vida, que pudesse contribuir para una formação mais voltada aos ditames da contemporaneidade.

\section{Premissas Metodológicas}

Mesmo que à guisa de mostrar-se redundante na obviedade, nunca é demais trazer-se a baila a crise paradigmática, por que passa a sociedade neste início de centuria. Crise que, sem dúvida, não pode passar alheia a própria concepção da ciéncia, mormente quando as ciências perquirem sobre sua própria fundamentação. A questão se volta ao cientificismo. Sem dúvida, a própria noção de conhecimento é mais uma vez trazida a indagação. A filosolia retoma seu lugar de destaque, tornando-se como que um modismo. A certeza das conclusóes obtidas pela ciencia, se por um lado atingem níveis de perfeição para o desenvolvimento tecnológico, por outro 
lado näo têm atingido as respostas para a complexidade da natureza humana. As antigas teorias são retomadas, na busca de refúgio diante do avanço cientifico-tecnológico, que permite avultem as investidas no mais impenetrável dos recônditos humanos em sua essencialidade, qual seja nos seus valores. A própria pretendida neutralidade axiólogica da ciência é, pois, no limiar do segundo milenio, posta em discussão. O presente projeto de ensino voltou-se à essa preocupação

\subsection{Sistema e tópica}

Na ciência jurídica a noção de sistema é introduzida por obra do jusnaturalismo racionalista, da Escola Histórica do Direito e do pandectismo. Observa-se, que em maior ou menor escala, com os aportes decisivos do normativismo positivista, a Jurisprudencia tem-se caracterizado pela construção sistemática e lógico-formal, orientada pelas idéias de unidade, plenitude e coerência do direito.

A idéa de sistema para o direito, em pouco difere da sua noção genérica. Entende-se por sistema, de um modo geral, um conjunto de elementos inter-relacionados; isto é uma entidade composta de, pelo menos, dois elementos, e em que cada elemento se relaciona a outro, direta ou indiretamente.

Costuma-se falar em sistema fechado, para designar o sistema que näo se abre para um ambiente, isto é, que năo possui um ambiente. Seus elementos interagem apenas entre si, sem qualquer comunicaça com elementos externos ao sistema.

Já por sistema aberto, compreende-se aquele contido num ambiente. Seu estado sofre influência de elementos, que não pertencem ao sistema. 0 sistema aberto tanto pode ser influenciado pelo ambiente, como pode influenciá-lo. Dai que, num sistema aberto, pode existir a entrada, que significa o aproveitamento pelo sistema de um elemento produzido pelo ambiente, e saida, que significa o aproveitamento ou a influência de elemento do sistema pelo ou sobre o ambiente.

Aceita a idéia, pode-se falar que o sistema possui uma interface, que consiste no conjunto de suas entradas e saidas. 
A sistematicidade tem sido entendida como garantia de cientificidadade.

No paradigma cartesiano, o sistema pode ser entendido inteiramente a partir de suas das propriedades de suas partes. Trata-se al de uma abordagem analítica ou reducionista.

A partir do Século XX aflora a percepção de que os sistemas não podem ser entendidos pela análise. A propriedades das partes não são propriedade intrisecas, no entanto, podem ser entendidas dentro do contexto do todo mais amplo. Por essa perspectiva, a relação entre o todo e as partes foi invertida. Na abordagem sistêmica, por essa percepçăo, as propriedades das partes podem ser entendidas apenas a partir da organização do todo. Desse modo, o pensamento sistêmico concentra-se não nos elementos de construção básicos, mas nos principios de organização básicos. Dado que a análise consiste no isolamento de alguma coisa, afim de entende-la e o pensamento sistêmico nos princípios organizacionais do todo, este se apresenta contextualmente, ou seja, pelo pensamento sistêmico insere-se alguma coisa no contexto de algo maior, para poder entende-la.

É a visão holistica contrapondo-se à visão reducionista. Ou seja, enquanto a primeira perspectiva dá ênfase ao todo, a segunda dá prioridade as partes.

O sistema representa, na ciência do direito, referencial obrigatório, pressuposto e limite da interpretação jurídica. Assim, em princípio, aplica-se à hermenêutica constitucional a técnica sistemática clássica, posto que as normas constitucionais, em essência, sāo nomas de direito.

Tendo em vista, porém, sua diversa natureza, funçāo e finalidade, apresentam as mesmas características próprias. Ademais, mostra-se insuficiente a interpretação sistemática tradicional, reduzida a termos lógicoformais, em face da compreensão material da Constituição.

A visăo lógico-sistemática da Constituição é superada pela reformulação do seu conceito, aduzindo-se as dimensões política, sociológica e filosófica. Surge uma teoria material da Constituição, impondo a concepção integral do sistema constitucional, na complexidade e 
complementariedade de seus elementos, notadamente os de natureza substancial. O sistema constitucional é agora sistema abetto de regras e principios, onde sobressaem os sentidos axiológico e teleológico das normas constitucionais e sua conexão com a realidade.

Não obstante permaneça ainda a noção sistêmica a condicionar a interpretação constitucional, percebe-se uma atenuação no seu rigor, obtida através das idéias de abertura do sistema e pela teoria material da Constituiçăo, o que propiciou o aparecimento de teorias hermenêuticas de inspiraçio tópica.

A tópica surgiu na Grécia antiga através de Aristóteles. Tal como concebida por ele, constitui um método ou teoria da argumentação em geral que opera por raciocínios dialéticos, que partem de opinióes verossímeis, diferentes dos raciocínios demonstrativos, que são próprios do conhecimento cientifico, porque partem de premissas tidas como verdadeiras e primeiras, indiscutiveis. Tópicos são os pontos de vista que permitem encontrar as conclusóes dialéticas.

Entre os romanos a Tópica de Cícero, Fundamentada na tópica aristotélica, caracteriza-se já como práxis de argumentaçâ. Sendo a experiência jundica romana predominantemente casuística e empirica, entende-se que a tópica foi característica do seu pensamento juridico e que os princípios e regras de direito representavam topois, na qualidade de sinteses das soluçoes de casos particulares.

Desde meados deste século reavaliam-se as possibilidades de uma tópica jurdica, por oposição à sistemática, considerando-se o pensamento problemático como o peculiar, próprio do direito.

Na observação da tópica, o principal ponto que se destaca é a constatação de que se trata de um técnica de pensar, orientada para problemas' Como a estruturação da ciência juridica é definida a partir do problema e em relerencia a este, seus conceitos e enunciados estâo estritamente vinculados a problemas e só podem ser entendidos a partir deles.

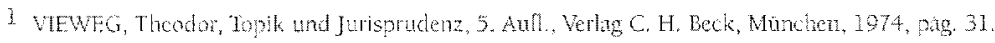


Diferencia-se do pensamento sistêmico pois que este pressupōe a existência de uma solução ${ }^{2}$, enquanto que a tópica desenvolveria um pensamento sobre o problema para o qual o sistema não pressuporia um solução .

Merece aqui ser frisado, todavia, que sistemática e tópica, como métodos de interpretação do direito, na verdade se completam na busca de realizaçăo da justiça, em sua forma mais expressiva, que é a isonomia ${ }^{3}$.

O muitas vezes propalado antagonismo entre sistema e tópica, como bem observado por parte da doutrinat, não deslez o prestígio da nova técnica, que prospera como base de reformulação a muitas correntes devotadas ao problema metodológico e principalmente ao trabalho interpretativo na ciência do direito.

Parece restar claro que nem a idéia de sistema está superada, nem existe na verdade antagonismo entre a sistemática e a tópica, concebida cada uma dessas idéias nos seus devidos termos, ambas tendentes à realizaçāo da justiça. Na verdade, a tópica completa a idéia de direito como sistema. Na medida em que preconiza a necessidade do intérprete para o caso concreto, realça a necessidade da atenção para as peculiaridades de cada caso, o que exige tratamento diferente na medida de suas diferenças 5 .

\subsection{Eleição do método}

Frisou-se no projeto a năo eleição de método unico para a congregacão dos elementos informativos e prospectivos voltados ao enfrentamento dos aspectos relevantes ao tema e ao deslinde das questóes ali envolvidas. Preconizou-se, sim empregar técnica de problematização aliada aos métodos do direito. É por que näo se pode dizer que a tópica, modernamente, possa ser considerada método propriamente dito. É mais

\footnotetext{
${ }^{2}$ WWEG, Theodor, Topik und Jurisprudenz, 5. Aul, verlag C. H. Beck, Muncher, 1974, pág. 33

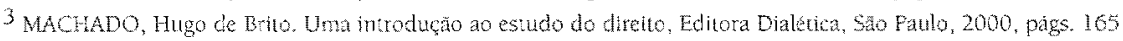

4 BONAVIDES, Paulo. Curso de dreito conslitucional, $7^{*}$ ed. Matheiros, Sảo Paulo, $1097, \mathrm{p} .450$.

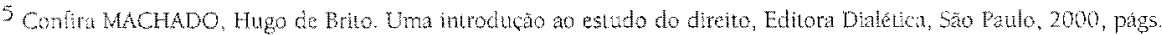


uma técnica de pensamento orientada para problemas. Não se trata, pois, de um procedimento de verificabilidade rigorosa". Na visão fundante da técnica, a interpretaçäo, atividade necessária no pensamento juridico, desenvolve-se dentro do estilo tópico. O que garante a permanência de uma ordem juridica, em face de certos câmbios sociais no correr do tempo, é justamente esse estilo flexivel em que os problemas são pontos de partida, que impedem o enrijecimento das nomas interpretadas ${ }^{7}$.

Vem-se buscando, portanto, empregar a técnica tópica para desvendar problemas e confrontá-los. Aliados à técnica argumentativa säo realçados, sem dúvida, os aspectos lógico-axiomáticos e lógico-deônticos. E que somente um sistema dedutivo, permite a verificabilidade lógica de seus preceitos ${ }^{8}$. No entanto, se a estrutura do direito é lógica, seu conteúdo ou sua fundamentação é, sem dúvida, axiológica. Na esfera da dogmática jurídica, como destacado por WARAT', os tópicos por essa visăo podem ser equiparados aos princípios gerais do direito. $O$ direito é, por essa forma, um pensamento por princípios, em torno dos quais se ordena todo o particularissimo das regras e dos atos concretos.

\section{Importância dos principios do Direito}

A teoria dos principios pode ser encarada por duas faces: a substantiva, relativa ao conteúdo de direito e a metodológica que diz respeito aos mecanismos de interpretação e aplicação.

O enfrentamento com os valores induz a percepcão de que se deve buscar refúgio em princípios, ao invés do excessivo apego às regras. Não quer isto significar desconsideração do direito ao papel das regras. O próprio direito só e verificável numa estrutura normativa, que é necessária para disciplinar determinadas relaçoes ou a impor determinada orientaçào. Mas é

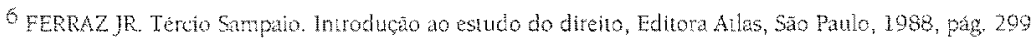

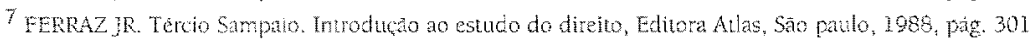

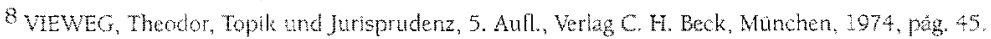

9 WARA, LuS Aberto. O dreito sua lighagem, Sergio Antonio Fabris Editor, Porlo Alegre, 1984. pag. 97.
} 
necessário que näo caia no olvide o fato de que uma ordem jurídica se fundamenta em princípios que, como o próprio nome sugere, constituem as suas idéias primeiras. Dai falar-se em princípios gerais do direito.

No ordenamento jurídico pátrio estão elencados com força de lei, assim, numa estrutura de modelos prescritivos, alguns desses princípios gerais de direito, o que não lhes altera a substanncia. É que se revestidos de Corca cogente, posto que o principio constitutivo do direito é a imperatividade, prevalece ainda indene o princípio em si régulativo do direito, que é quem the confere sentido. A noção de sentido se liga à idéia de urn senso comum. À prospecção desse sentido, dentro da idéia de um senso comum, não só de um senso natural comum a todos, mas decorrente mesmo da vivência num mundo comum, é que afigura-se apropriada a técnica tópica, preconizada no projeto.

\section{Desenvolvimento do projeto}

Tomando-se em conta que no aspecto lógico, os princípios podem ser ticlos como verdades embasadoras de um sistema de conhecimentos, admitidas como tais, seja por evidência ou por comprovação, seja ainda por imposição de ordem prática de caráter operacional ${ }^{10}$, buscou-se aprioristicamente o delineamento conceitual, para entăo estabelecer as estratégias e fixar os métodos de trabalho.

Uma das experiencias processadas com os partícipes, consistiu na tentativa de agrupar as significaçōes vislumbradas sobre a própria expressão princípios. Com lastro no dispositivo do artigo 37 da Constituiçăo Federal, buscou-se instigar o grupo a exteriorizar o entendimento dos ali contemplados princípios.

As primeiras investidas se restringiram à focalizaçäo isolada do instituto. Portanto, à localização no sistema. Os questionamentos acerca da significaçăo de cada um dos princípios é que propiciaram a constatação, de

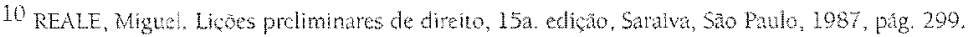


que a localizaça no sistema, por si, em nada subsidiava as exigidas respostas. Em termos de argumentação, a localização topográfica nada acrescia aos questionamentos, exceto quando analisados numa visão sistèmica. Daí que novas tarefas foram distribuidas, na busca de topois argumentativos sistemáticos. O grupo deu-se então conta, de que o sistema mesmo pressupóe uma fundamentação, identificada no preâmbulo da Constituiçảo.

De ai para a compreensão do fenomeno normativo numa tridimensionalidade conceitual, fó um passo. Os argumentos, portanto, não poderiam ficar adstritos ao campo do positivismo lógico. Como o grupo constatou, as estruturas lógicas permitem a elucidaçáo do fenômeno juridico no seu aspecto proposicional, através de juizos do ser, ou juízos daquilo que é, ou seja a norma em si. Mas, constataram também que, como já ensinava KANT, é impossivel extrair daquilo que é, aquilo que deve ser, o valor. Os preceitos do dever ser, ou seja, os juizos de valor nâo podem ter sua fundamentação preenchida indutivamente das verificaçoes do existente, mas sim dedutivamente de outros preceitos, outros juizo de valor, de identica natureza. Em conclusäo, para o grupo, os principios no direito só poderiam ser apreendidos como fatos culturais. Da mesma forma, que é a idéia do principio juńdico, quem fundamenta o preceito juridico. Assim, os principios jurídicos, como conceitos aprioristicos, orientariam os preceitos, que se colocam como meios para a realização de certos valores.

Isso permitiu ao grupo uma visão pelo menos dual do direito. Por uma, que os principios constituem-se em categorias. Por outra, que os princípios constituem-se em telos, ou seja em meios para a realização da idéia. Mas, os princípios também estão categorizados em relação a fatos, a situaçóes de fato a que eles se amoldam, em razão de valores. Os princípios juridicos e consequentemente os princípios da administração pública, têm uma natureza cultural compreensival!

Essas fases do projeto, foram as que mereceram um grande esforco, no sentido de despertar o raciocínio para a problematizaçăo. Não se quis

11 Compare RADIRUCH, Gustax lisolia do direito, 6a, edică, Armenio amado Editor, Coimbra, 1979, pag 244 
empregar o direcionismo, mas sim a auto motivaça. Os discentes, escorados que se achavam, em ter suas tarefas adredemente atribuidas mostraram inicialmente certa dificuldade em movimentarem-se com autonomia. A problematizaçấ, quando espontânea, restringia-se à modelos já perquiridos pelos autores levantados pelos mesmos, em número restrito aos referentes à bibliogralia básica da disciplina.

A compreensão necessâria para o estabelecimento espontảneo das estratégias, teve inicio quando da fixação dos métodos e de mais ampla pesquisa bibliográlica. Ocasião em que as discussões se avolumaram e podese mesmo iniciar a tabulaçăo dos dados, com que se pretende dar continuidade ao planejado. É que nessa fase, utilizavam-se nào somente a teoria, mas também a jurisprudéncia. E, com base nos julgados, é que o trabatho veio a se desenvolver num ritmo mais harmonioso, embora acalentado por discussóes no vislumbre e escolha dos topoi.

Adololi-se, pois, a jurisprudência por constituir-se em fonte do direito, ademais por inferir-se residir na necessidade de fundamentação das decisoes judiciais grande poder de legitimação, haja vista o contido na Constituiça Federal, em seu artigo 93, IX, prescrevendo que: todos os julgamentos dos ógão do Poder Judiciário serão públicos, e fundamentadas todas as decisóes, sob pena de nulidade... A técnica da argumentação configurar-se-ia aqui como instância dialética visando prescuutar sobre a razoabilidade de decisöes enfrentadas.

Com efeito, ao se considerar um problema, despontam diversas indagacôes. Como a tópica é a teoria dos lugares comuns, o conhecimento desses lugares, que se constituem em repertórios, facilita a compreensão. A tentativa, pois, se deu na verificaça das premissas que conduziram às decisões judiciais enfocadas.

Admitindo-se a ampla participação dos integrantes como intérpretes, à medida que se concluisse por ter a decisão como racionalmente correta, poder-se-ia considera-la adequada ou verdadeira. Adequada no sentido de ser capaz de convencer sobre a sua razoabilidade e verdadeira, na medida em que, com base nos topoi de senso comum, de forma definitiva, a interpretaçăo pudesse visiumbrar resultados práticos, capazes de alterar a realidade. 
Nesse ponto, voltou-se o realce à importância dos princípios no ordenamento juridico. Afinal, são eles que, mesmo num plano supraconstitucional, vão servir de farol indicador das consequências, que se pretende extrair das normas jurídicas, tanto no plano hierárquico constitucional, quanto no plano das normas ordinárias. Digna de nota, nessa fase foí a constatação da compreensão, por parte do grupo, de que não se pode conceber de forma absoluta uma hierarquia constitucional dos principios que a orientam, porquanto consubstanciados em valores fundamentais transcendentes ao poder constituido, aos quais ele se acolmata. Além đisso, por que é também um principio constitucional, que afasta uma pretensa hierarquia absoluta, o da proporcionalidade.

\section{Conclusão}

Os aspectos aqui levantados, sem dúvida, năo passaram desapercebidos aos integrantes do projeto. Sendo certo, também, que até determinado estágio, ainda se fez necessária uma coordenação mais diretiva do que seletiva.

O momento que seguiu, todavia, foi justamente o da análise crítica dos resultados até então obtidos. Percebeu-se, entäo, uma crescente autonomia, resultante da análise das posturas adotadas nos relatórios e conclusöes.

Em síntese, pode-se dizer que o projeto mostrou resultados satislatórios, mormente no que diz respeito à livre iniciativa do registro das pesquisas em formataçáo monográlica, por parte da maioria dos participes, com vistas à sistematização dos resultados.

\section{BIBLIOGRAFIA}

BONAVIDES, Pallo, Curso de direito constitucional, $7^{2}$ ed., Maheiros, São Paulo, 1907 FERRAZ JR. Tércio Sampaio. Introduçăo ao estudo do direito, Editora Atlas, São paulo, 1988. MACHADO, Hugo de Brito. Una introduçäo ao estudo do direito. Editora Dialética, Săo Paulo, 2000 REALE, Miguel. Liçoes preliminares de direito, 15a. ediçẵo, Saraiva, São paulo, 1987. RADBRUCH, Gustav Fisola do direito, 6a. ediça, Armento amado Editor, Coimbra, 1979 VIEWEG, Theodor, Topil und Jurisprudenz, 5. Auf., Verlag C. H. Beck, München, 1974 WARAT, Luis Albero. O direito esua linguagem, Sergio Antonio Fabris Editot, Porto Alegre, 1984 